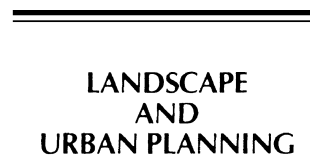

Landscape and Urban Planning 49 (2000) 25-34

www.elsevier.com/locate/landurbplan

\title{
A conceptual framework for integrating hydrological and biological indicators into watershed management
}

\author{
Chansheng $\mathrm{He}^{\mathrm{a}, *}$, Stephen B. Malcolm ${ }^{\mathrm{b}}$, Kenneth A. Dahlberg ${ }^{\mathrm{c}}$, Bojie Fu ${ }^{\mathrm{d}}$ \\ ${ }^{a}$ Department of Geography, College of Arts and Sciences, Western Michigan University, Kalamazoo, MI 49008-5053, USA \\ ${ }^{\mathrm{b}}$ Department of Biological Sciences, Western Michigan University, Kalamazoo, MI 49008-5053, USA \\ ${ }^{\mathrm{c}}$ Department of Political Science, Western Michigan University, Kalamazoo, MI 49008-5053, USA \\ ${ }^{\mathrm{d}}$ Research Center for Eco-Environmental Science, Chinese Academy of Sciences, Beijing 100085, PR China
}

Received 16 October 1999; received in revised form 7 December 1999; accepted 21 January 2000

\begin{abstract}
Development of integrated ecological indicators for assessment of the condition of altered watersheds is fundamental to sound policy and decision making in water resource management. This paper proposes a conceptual framework for developing and integrating a set of hydrological and biologic indicators that can show the modified spatial and temporal distributions of hydrological and biological conditions which result from land use/cover changes across the study watersheds by using Geographic Information Systems, remote sensing, multiple physical and biological databases, and simulation models. Effects of management practices and programs can be evaluated by comparing the temporal distributions of these indicators over a certain period. The paper further outlines steps needed to bridge the gaps between the largely physical and structural aspects of research on watershed indicators and the work on biological processes and indicators of ecosystems for integrating these indicators into watershed planning and management processes. (C) 2000 Elsevier Science B.V. All rights reserved.
\end{abstract}

Keywords: Indicators; Watersheds; Ecosystems; Planning and management

\section{Introduction}

Development of a set of readily measurable indicators which describe the condition and health of watersheds is essential to protection and sustainable use of terrestrial water resources. In recent years, a number of studies have focused on the indicator development. For example, 'The Freshwater Imperative', a book collectively sponsored by multiple US

\footnotetext{
* Corresponding author. Tel.: +1-616-387-3425; fax: +1-616-3876-3442.

E-mail address: he@wmich.edu (C. He)
}

Federal Agencies, calls for the development of appropriate indicators to track particular environmental changes and their effects on ecological services, human health, aesthetic and recreational activities, and the degree of integration of human, natural, and management sciences in freshwater research and management (Naiman et al., 1995). A central theme of the US Environmental Protection Agency's (EPA) Environmental Monitoring and Assessment Program (EMAP) is similarly focused on the development of ecological indicators to estimate the state and health of the nation's ecological resources on a regional basis (Messer et al., 1991). The US Geological Survey's 
National Water Quality Assessment Program (NAWQA) places its emphasis on inventory, monitoring, and assessment of water resource conditions. In working with public and private partnerships, the USEPA has developed a set of indicators to measure the water quality of the nation's watersheds (USEPA, 1996, 1997). At the landscape scale, researchers have proposed the index of biotic integrity which integrates 12 attributes of fish assemblages to evaluate the ecological quality of a water resource (Karr et al., 1986) and indicators of ecosystem recovery which reflect intrinsic importance, processes, sensitivity, and effects of ecosystems (Kelly and Harwell, 1990). These indicators, however, are often based on single purpose such as vegetation, soil, hydrology, or climate frameworks (Bailey, 1984; Omernik, 1995) and often reflect the partial state of an ecosystem. A set of indices such as an ecological index of integrity which describe the patterns and processes of an ecosystem holistically should be developed to evaluate the state of the ecosystem (Omernik, 1995). These type of indices, while critical to natural resource assessment and management, have yet to be developed (Omernik, 1995).

This paper proposes a framework to develop, and test a set of hydrological and biological indicators that reflect the condition of watersheds, particularly rural watersheds over spatial scales from a few hundred to a few thousand square kilometers. We first discuss the rationale of our conceptual framework, and then describe procedures for deriving watershed indicators from remote sensing and Geographic Information System (GIS) databases. Finally, we outline how the indicators can be used in support of watershed planning.

\section{Context}

Changes in landscape structure will result in changes in the flows of energy and nutrients and the number and composition of species (Turner, 1989). In a natural watershed environment, structural changes of the watershed landscape are relatively slow (except under the condition of natural disasters such as fire, drought, and flood) and the watershed landscape is able to maintain a balanced community of organisms (Karr et al., 1986; Likens, 1987). In many regions of the world, however, human activities have vastly altered the structure of natural watersheds and their ecosystems through accelerated conversion of forest land and wetlands to agricultural or urban land, excessive application of fertilizers and pesticides, vast modifications of hydrological pathways, and concentrated industrial development. As a result, the distributions of energy and matter fluxes in the watersheds and their ecosystems have also been altered both spatially and temporally (Karr et al., 1986; Turner, 1989; Naiman et al., 1995). These fluxes include solar radiation, temperature, precipitation, evapotranspiration, surface runoff, discharge, nutrient availability (nitrogen and phosphorus), soil erosion and sedimentation, toxins, patch dynamics, and animal movement (Hobbs, 1997).

With the rapid advances in the computing technology, increasingly easier access to huge amount of high resolution remote sensing imagery and multiple social, economic, and biophysical databases, and improving analytical capability of GIS, changes in land cover can be readily detected through image processing and analysis. The distributions of the energy and material fluxes from the changed land cover over space and time can also be monitored and assessed using remote sensing, GIS, and simulation models. As shown in Fig. 1, by integrating multiple databases of satellite imagery and aerial photographs, soils, digital elevation, river reach files, and population distributions, the types and geographic extent of land cover can be derived based on a classification system such as those of Anderson et al. (1976) and Cowardin et al. (1979). In the meantime, geographic analysis can be done using GIS and simulation models to determine landscape pattern indicators such as patches, edges, and species diversity, and resultant energy and matter fluxes including solar energy, temperature, evapotranspiration, normalized differential vegetation index (NDVI) nutrients, soil erosion and sedimentation, and biological oxygen demand, etc. These indices can help management agencies better detect and evaluate the condition of watersheds, especially in rural watersheds of a few hundred to a few thousand square kilometers, and subsequently solicit public support for and stakeholder participation in taking appropriate measures to ensure the maintenance of designated beneficial uses in the watershed (Fig. 1). Furthermore, these analyses and 


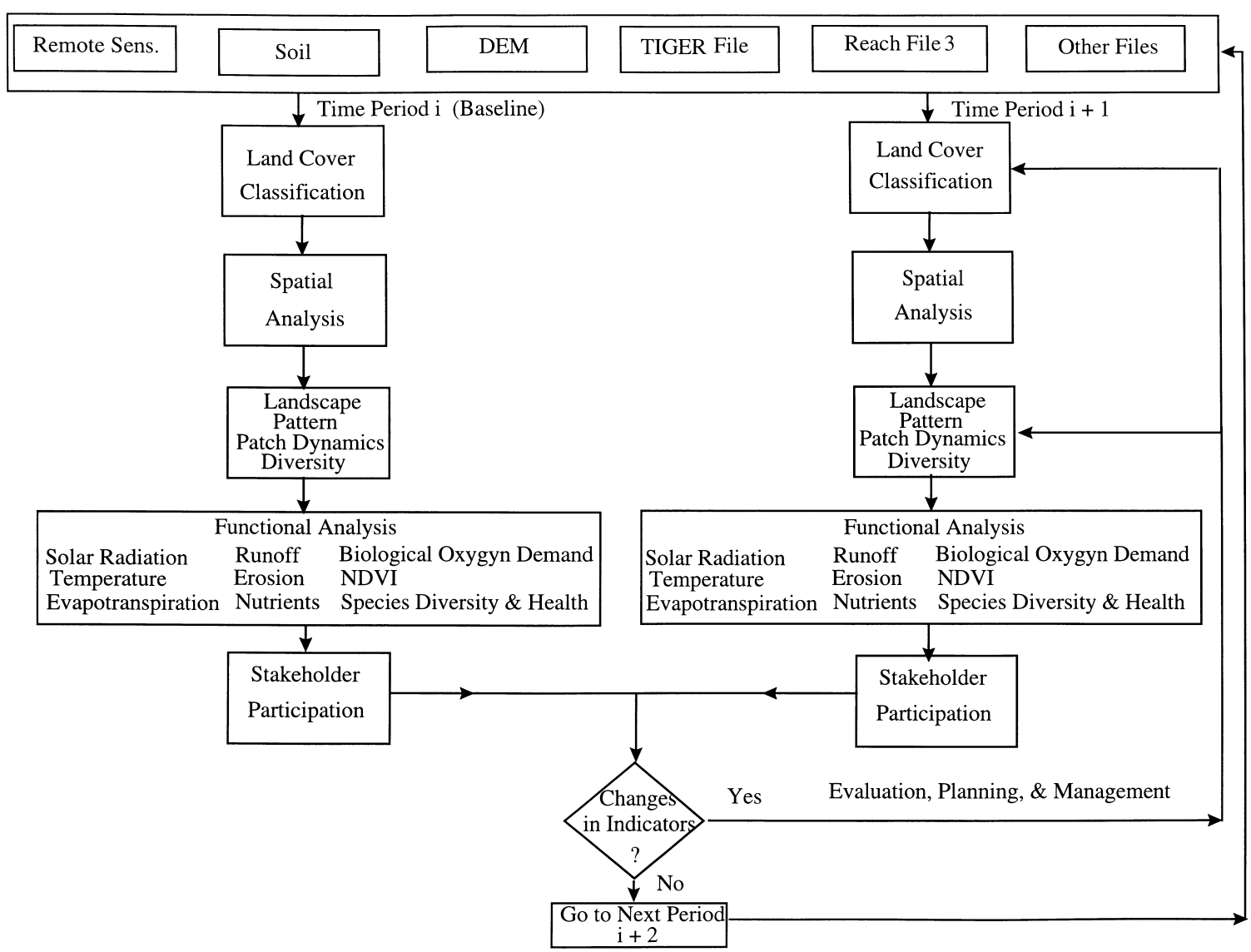

Fig. 1. A conceptual framework for the development of watershed indicators.

indicators can also be used to evaluate whether current policies and management practices are working as planned in restoring or enhancing the designated beneficial uses of the watershed. For example, a set of ecological indicators derived for a watershed from a baseline period (Period 1, e.g. 1985) can be compared to the same indicators for a different period (Period 2, e.g. 1995) in the same landscape or to an unperturbed watershed to reveal whether the adopted management actions are working. If these indices are compared to the designated uses specified in the study watershed management plan, these could be used for improving the modeling of structure- function interactions of the watersheds. A major advantage of this approach is the use of readily available, remotely sensed data and other multiple databases to monitor and assess changes in the structures and functions of watersheds and their ecosystems on a continuous basis at the regional scale. Such information might not be readily available or as clearly apparent by monitoring population levels of certain species such as fish in individual sites (Kelly and Harwell, 1990; Hobbs, 1997).

\section{Analysis procedure}

Management of watersheds requires the integration of natural, biological, and management sciences at the watershed scale. Two key research questions in this process are: what biological, hydrological, and social economic indicators can be used to best represent the condition of watersheds and their ecosystems? And how can these indicators be used in support of planning, management, and rehabilitation efforts? Kelly 
and Harwell (1990) discuss the criteria for selecting ecological indicators, which include sensitivity to stress, rapid response, reliability of response, ease/ economy of monitoring, and feedback to regulation or management, etc. That is, a set of the selected indicators should produce fast, sensitive, specific, and reliable responses to stress, and at the same time, are relatively easy or inexpensive to develop and practical to management decision making at multiple spatial and temporal scales. Ferguson (1994, 1996) defines attributes of the landscape health as openness, self-regulation, storage and diversity. He points out that no single indicators such as slope, sediment, diversity, productivity can indicate, by itself, if a landscape is in an equilibrium in or near the home state. In this paper, we propose a framework to attempt to address the two questions. In following sections, we describe the three stages for development of the hydrological and biological indicators for watershed analysis 1, analysis of land use/cover change; 2, development of indicators; and 3, stakeholder participation.

\subsection{Analysis of land use/cover changes over space and time}

Landscape patterns change constantly. In a natural environment, these changes are in an equilibrium state and evolve slowly. In an anthropogenically stressed ecosystem, the changes in the landscape structure are artificially accelerated and the habitats in the landscape are often altered, damaged, or destroyed. Management of the habitats in a landscape involves evaluating land cover change over space and time. Modification of the existing landscape structure to move it toward a 'desirable' state (i.e. supporting designated uses) is the overall goal of watershed management (Karr et al., 1986; Turner, 1989).

To analyze land cover change, remote sensing data including satellite imagery (e.g. LANDSAT, SPOT, RADARSAT, and more recently the launching of $1 \mathrm{~m}$ resolution imagery commercial satellite by Space Imaging Co.) and high resolution $(1: 24,000)$ aerial photographs can be used to estimate land use/cover types in the study watershed for a desirable time period (e.g. 20 or 40 years, Fig. 1). In the US, appropriate aerial photographs have been available since 1937 for most counties and satellite imagery (LAND-
SAT MSS) started in 1972. Digital soil data such as State Soil Geographic database (STATSGO), digital elevation model (DEM), the census Topologically Integrated Geographic Encoding and Referencing (TIGER) file, and other base files can be used to help categorize the land use/cover types (Fig. 1). The classification system of Anderson et al. (1976) and of Cowardin et al. (1979) can be used in determining land cover types. Dependent upon the availability and resolution of aerial photographs and satellite imagery, the level II land use/cover classification (of Anderson et al.) can be achieved. Historical land cover maps and relevant government records can also be used to assist with the land cover classification. For example, Zheng et al. (1997) used LANDSAT images and change detection method to analyze the rates and patterns of landscape change between 1972 and 1988 in a forest reserve area in China and North Korea. Knick and Rotenberry (1997) assessed the impact of type and frequency of anthropogenic disturbance (agriculture, wildfires, and artificial fires) on the conversion of shrublands to annual grasslands in southwestern Idaho by analyzing landscape characteristics of the study area using LANDSAT imagery.

\subsection{Development of hydrological and biological indicators}

The classified land cover/use files can be used in GIS to characterize the landscape structures including number, size, shape, and distribution of patches and edges among different land cover categories of the landscape because changes in these categories over time determine the dynamics of interactions among the individual landscape components. A number of measures such as species richness and evenness, habitat diversity, edges and fragmentation can be used to quantify the landscape structures (see Fig. 1, Turner, 1989). In addition, GIS analyses can be conducted to identify and analyze the size, shape, number and distribution of wetland forms and urban areas (Jensen et al., 1986, 1993, 1997).

The structure of a landscape determines the flow of energy, materials, and organisms among the components of the landscape (Turner, 1989). Analysis of the flow of energy and materials and distribution of habitat in the landscape can indicate the performance of the landscape structure. Since "no unique characterization 
of an ecosystem exists' (Kelly and Harwell, 1990; Ferguson, 1996), we choose (A) water quality, (B) evapotranspiration (ET) and runoff rates, and (C) species diversity and health as indicators of landscape structure and function.

\subsubsection{Water quality}

Nonpoint source (NPS) pollution is related to climate, soil, topography, land cover/use, and management practices. Changes in landscape structure will result in changes in NPS loading including erosion, sedimentation and nutrient runoff, especially in rural watersheds. A number of models such as universal soil loss equation (USLE, Wischmeier and Smith, 1965), areal nonpoint source watershed environment response simulation (ANSWERS, Beasley et al., 1980), hydrologic simulation program FORTRAN (HSPF Bicknell et al., 1993), storm-water management model (SWMM, Huber et al., 1981), agricultural nonpoint source pollution model (AGNPS, Young et al., 1987), erosion/productivity impact calculator (EPIC, Sharpley and Williams, 1990), and water erosion prediction program (WEPP, Flanagan and Nearing, 1995) have been developed to estimate runoff, soil erosion and sedimentation for both urban and rural watersheds. For example, the AGNPS model can be used to evaluate the relationships between land use/ cover and the resultant nutrient runoff and sedimentation. The simulated sedimentation and nutrient runoff from both agricultural land and urban land will partially indicate the performance of the watershed landscape structure. The greater the runoff and soil erosion, the more severe the adverse impact on water quality and habitat, which is an indication of unhealthy landscape structure. He et al. (1993, 1999) have integrated AGNPS with GRASS and ArcView GIS to evaluate the impact of agricultural runoff on water quality in an agricultural watershed. The basic databases needed include climate, land cover, digital elevation, soil, hydrography, crop statistics and information on management practices. Outputs of the model include spatially distributed estimates of peak runoff, overland and channel erosion, sediment yields, and concentrations of nitrogen and phosphorus. In a case study of predominantly agricultural watershed, He et al. (1999) report that runoff and soil erosion are closely related to land use, topography, and management practices.
One should note that any watershed model is an abstraction of the real watershed system. Field sampling needs to be conducted to verify some of the model input parameters such as slope length, soil nutrient level (nitrogen and phosphorus), and the model simulated results such as peak runoff and sediment in the study watersheds in order to determine the uncertainty of the simulated results.

Other methods can also be used to evaluate the effect of land use change on water quality. Mattikalli and Richards (1996) develop historical land use/cover maps for a rural watershed in eastern England using the land utilization survey data, aerial photographs, LANDSAT MSS and TM, and SPOT images of 19311989. They further produce maps showing land cover change dynamics of the watershed through land cover change detection analysis. On this basis, they use the export coefficient model to compute nitrogen loading for each land use category to evaluate the effects of land use changes on the water quality. The fertilizer application rates were acquired from literature. The nitrogen loss was calculated based on the land use classes and fertilizer application rates. The results indicate that changes in both land use classes and fertilizer application rates led to the increased nitrogen loading in the watershed. Larsen et al. (1988) analyzed the relationship of landscape patterns and water quality in Ohio's 107 watersheds and concluded that landscape patterns significantly affect surface water quality. Landscape patterns and water quality in minimally impacted watersheds can serve as reference sites for managing water quality in the severely impacted watersheds.

\subsubsection{ET and runoff}

The distribution of energy and vapor fluxes in a landscape is a function of the landscape structure, climate, and topography. Measurement of these fluxes over a relatively large area can reveal how the surface conditions of our environment change. Since the ET rate is an indication of the ability of plants to use water from the environment, estimation of plant ET rate can help us to determine how well plants adapt and respond to shifts in the structure of the landscape. With remote sensing technology, the energy and vapor fluxes can be estimated rapidly over a large area. The energy balance and mass transfer model suggested by Fuchs and Tanner 
(1967) can be used to evaluate changes in net radiation and ET rate resulting from the structural changes of the landscape. The main advantages of this approach are that (a) the energy and vapor fluxes can be calculated on a fine grid of cells over the entire study area, (b) it links the environmental factors which include solar radiation, temperature, precipitation, and soil with the health of vegetation, and (c) it incorporates key surface parameters such as surface temperature and albedo that can be directly obtained from satellite data.

Estimation of net radiation at the watershed scale can be obtained from (Bartholic et al., 1970)

$R_{\mathrm{n}}=Q_{\mathrm{s}}-Q_{\mathrm{sr}}+Q_{\mathrm{a}}-Q_{\mathrm{ar}}-Q_{\mathrm{bs}}$

where $R_{\mathrm{n}}$ is net radiation flux density (cal. $\mathrm{cm}^{-2} \mathrm{~min}^{-1}$ ), $Q_{\text {s }}$ is incoming solar radiation flux density (cal. $\mathrm{cm}^{-2}$ $\left.\min ^{-1}\right), Q_{\text {sr }}$ is reflected solar radiation flux density (cal. $\mathrm{cm}^{-2} \min ^{-1}$ ), $Q_{\mathrm{a}}$ is incoming thermal radiation flux density from the atmosphere (cal. $\mathrm{cm}^{-2} \mathrm{~min}^{-1}$ ), $Q_{\mathrm{ar}}$ is reflected thermal radiation flux density (cal. $\mathrm{cm}^{-2}$ $\left.\min ^{-1}\right), Q_{\mathrm{bs}}$ is emitted thermal radiation flux density (cal. $\mathrm{cm}^{-2} \min ^{-1}$ ). $Q_{\mathrm{s}}$ can be estimated from GOES visible data and $Q_{\mathrm{sr}}, Q_{\mathrm{a}}, Q_{\mathrm{ar}}$, and $Q_{\mathrm{bs}}$ by other satellite data such as NOAA, AVHRR and LANDSAT (Gautier et al., 1980; Jackson et al., 1985; Reginato et al., 1985; He et al., 1987).

The Bowen ratio method (Bartholic et al., 1970) can be used to estimate evapotranspiration (ET) as shown below

$\mathrm{ET}=-\frac{R_{\mathrm{n}}+G}{[1+\gamma(\Delta T / \Delta e)]}$

where $G$ represents soil heat flux density (cal. $\mathrm{cm}^{-2}$ $\left.\mathrm{mm}^{-1}\right), \gamma$ is the psychometric constant, $\Delta T$ is the temperature difference between surface temperature $T_{\mathrm{o}}\left({ }^{\circ} \mathrm{C}\right)$ and air temperature $T_{\mathrm{a}}\left({ }^{\circ} \mathrm{C}\right)$, and $\Delta e$ is the vapor pressure difference between saturated water vapor pressure $\left(e_{\mathrm{a}}^{\prime}\right.$ in $\left.\mathrm{mb}\right)$ at $T_{\mathrm{a}}$ and saturated water vapor pressure $\left(e_{\mathrm{a}}^{\prime}\right.$ in $\left.\mathrm{mb}\right)$ at $T_{\mathrm{o}}$.

In the Bowen ratio method, net radiation $(\mathrm{Rn})$ can be computed from satellite data, soil heat flux density can be estimated as a fraction of the net radiation and the height of the plant canopy (Engman and Gurney, 1991), and air temperature $\left(T_{\mathrm{a}}\right)$ can be obtained from weather stations, while surface temperature $\left(T_{\mathrm{o}}\right)$ can be derived from satellite data, and saturated water vapor pressure $\left(\left(e_{\mathrm{a}}^{\prime}\right.\right.$ and $\left.\left.e_{\mathrm{o}}^{\prime}\right)\right)$ can be computed from $T_{\mathrm{a}}$ and $T_{\mathrm{o}}$, respectively (He et al., 1987; Engman and Gurney, 1991).

In humid regions, ET rates from wetland and forested land are generally greater than those from agricultural land and the ET rates are usually lowest from the urban land (He et al., 1987). Comparison of the distribution of net radiation and ET rates and peak runoff calculated from the models between a perturbed and an unperturbed watershed will help us understand how these values change across a landscape as a function of land cover classes.

For example, in studying global land surface evaporation, Choudhury et al. (1998) use a biophysical model and satellite and ancillary data to compute net radiation, sensible heat, and evaporative fluxes of the global surface. The results indicate that annual total evaporation over the global land surface comprises $52 \%$ transpiration, $28 \%$ soil evaporation, and $20 \%$ interception. Transpiration is the dominant component of annual total evaporation in the majority of global land surface. They examine the relationship of vegetation types and distribution of net radiation and total evaporation and report, for example, that the annual average values of net radiation (evaporative water equivalent) and total evaporation are 274 and 171 (mm per year) in Tundra area $\left(59-61^{\circ} \mathrm{N}, 71-76^{\circ} \mathrm{W}\right)$, 787 and 488 in Taiga $\left(52-54^{\circ} \mathrm{N}, 90-96^{\circ} \mathrm{W}\right), 1515$ and 1090 in Savanna $\left(15-18^{\circ} \mathrm{S}, 50-53^{\circ} \mathrm{W}\right), 1515$ and 1200 in rainforest $\left(2^{\circ} \mathrm{N}-2^{\circ} \mathrm{S}, 11.5-13^{\circ} \mathrm{E}\right)$, and 1041 and 639 in cropland $\left(40-41^{\circ}, 84-86^{\circ} \mathrm{W}\right)$, respectively.

\subsubsection{Species diversity and health}

Types, sizes, number, and distribution of land cover categories across the landscape of a watershed determine habitat characteristics and their associated species within included ecosystems. Modification of landscape structure (such as land cover types) and related energy and matter fluxes will likely lead to changes in habitats and species composition (Kelly and Harwell, 1990). Corresponding relationships, although not necessarily unique, exist between habitat characteristics and biological species. Thus, component ecosystems within a watershed landscape can be surveyed to measure species richness and evenness within habitat categories identified by GIS analysis as measure of landscape structure and 'health'. These measures include both stable and rapidly changing components in which biodiversity and integrity will be 
compared with the use of diversity indices and species abundance models (Magurran, 1988). Generally, anthropogenically perturbed environments shift from a log normal distribution of species abundance plotted against rank, with an increase in species dominance and a decrease in species richness (Magurran, 1988). In perturbed environments, species abundance distributions often reverse through successional series to become geometric and reflect less equability among the species and dominance of a small number of the commonest species (May, 1981). In deciduous forest, the distribution of species in rank abundance plots is typically log normal (Whittaker, 1970). In addition, comparisons of overall structural (architectural) diversity of the plant communities (Southwood et al., 1979), vertical diversity using the stratiscope method of Blondel and Cuvillier (1977), and horizontal spatial diversity by nearest neighbor distances within and among plant species (Southwood, 1978), will also be good indicators of the state, or 'health', of the study watershed landscape.

The same measurements can be made in both perturbed and control (unperturbed) watersheds so that the ecological impact of various anthropogenic disturbances can be assessed by statistical comparisons of structural and species diversity measurements and the fit of species abundance plots to the log normal distribution. The log normal distribution can be used as a criterion of comparative watershed vigor and health, and significant departures from this distribution, or a significant fit to a geometric series can both be used as objective criteria to establish that some form of watershed disruption has occurred. These data can then be used to compare with current GIS layers of habitat categories and to assess the degree and nature of long term changes across time series of historical images (Likens, 1987).

For example, Gove et al. $(1992,1995,1996)$ used plant species diversity measurements to compare preand post-treatment plant communities within watersheds subject to experimental deforestation in the northern hardwoods at the Hubbard Brook Experimental Forest in New Hampshire. Diversity indices and diversity profiles showed that an experimentally deforested watershed was less diverse than a forested control watershed immediately after deforestation, but that diversity increased and was significantly higher than the control after 10 years. Individual commu- nities within treatments could be tracked over time and spatial elements could also be compared at the same time or among time intervals. Different spatial scales were also compared and strip cuts in the forest were found to be intrinsically more diverse than clear-cut blocks 10 years after post cutting (Gove et al., 1996).

In 1973, Patrick showed that organic pollution could shift the species abundance distributions of diatoms in a Pennsylvania stream back through an ecological succession from the log normal pattern characteristic of a mature, unpolluted community, to a geometric series characteristic of a polluted community. These shifts reflect increasing slopes of species rank abundance curves as pollution increased and species diversity and species equitabilities decreased (Patrick, 1973). Similarly, the long term Park Grass experiment at Rothamsted in England, also shows a marked decrease in plant species diversity with continuous application of nitrogen fertilizer, from 49 species in 1856 to three species in 1949 and a dramatic increase in dominance of the commonest species from 14.5 to $99.7 \%$. Together these shifts were described by a species rank abundance distribution that changed from log normal to a geometric series (Tilman, 1986; Magurran, 1988).

\subsection{Stakeholder participation}

Successful watershed management requires close interaction and strong partnerships between local governments, industry, residents, community groups, and the research community. In order to incorporate the hydrological and biological indicators into the watershed planning process, the information needs of local policy decision makers, and the incentives and disincentives to effective use of the available watershed indicators and data in watershed restoration and rehabilitation have to be identified and considered through systematic interactions such as meetings, surveys, and discussions with relevant stakeholders. The outline below gives an overview of one way to organize such an effort and is meant to highlight the relevant factors that need to be included.

\subsubsection{The creation phase}

In this phase a small group develops the background and strategy to guide and co-ordinate the effective 
inclusion of research and indicators in watershed planning, management, and stakeholder participation in decision making. This should include (1) development of an initial vision and set of goals, (2) preliminary assessment of watershed problems and opportunities, and (3) identification of key stakeholders and solicitation of their participation in watershed planning process.

\subsubsection{The implementation phase}

In this phase the stakeholder group developed in Phase I goes through the same process as above, but in greater depth and with more specific focus on the research and the types of indicators that are needed for effective planning, management, and policy making. The tasks include (1) developing an initial vision and set of goals based on the broad watershed outcomes desired, (2) assessing resources, challenges, and opportunities available in the study watershed, (3) building the organization or network for watershed planning and management, paying particular attention to staff, funding, and organizational structure, (4) developing goals for research, indicator development and refinement, and policy with attention to bureaucratic and political feasibility, and (5) establishing an ongoing set of procedures for operation and evaluation of watershed planning and management.

Such a general process, adapted and applied to the specific organizational context within which watershed planning, management, and rehabilitation takes place will not only improve our understanding of the interactions among human, physical, hydrological, and biological processes in watersheds studied, but will also facilitate the interaction between research and management communities in integrating scientific data and information into watershed decision making processes. Palmer (1997), for example, uses aerial photographs of 1976 and 1987 to survey the local citizens' perceptions and reactions to landscape change in Cape Cod, Massachusetts, in support of the area's comprehensive land use planing.

\section{Summary}

Human-induced changes in landscape structure lead to modified spatial and temporal distributions of energy and matter fluxes and types and sizes of habitats at the watershed scale. This paper proposes a conceptual framework for developing and integrating a set of hydrological and biological indicators using remote sensing and multiple GIS databases for local watershed planning. A main advantage of this approach is use of readily available satellite data and other multiple databases for evaluation of watershed condition on a continuous basis, thus providing timely, watershed scale information to watershed planning and management. The paper further outlines the steps needed to bridge the gaps between the largely physical and structural aspects of research on watershed indicators and the work on biological processes and indicators of ecosystems for integrating these indicators into watershed planning and management processes.

Development of a set of appropriate indicators that produce fast, sensitive, specific, reliable, and inexpensive characterization of watershed conditions for watershed planning and management requires the integration of natural, biological, and social sciences at the watershed scale. Pickett et al. (1997) present a framework for the study of human ecosystems in urban areas and suggest use of a watershed approach to assess how urban, suburban, and rural land uses, management practices and social behaviors affect watershed structure and function. The conceptual framework in this paper represents our initial attempt to incorporate hydrological, biological, and social sciences in watershed indicator development to support watershed decision making. Although individual studies have been conducted to monitor and assess individual indicators, an integrated research to refine and test the proposed framework is in progress. We believe through integrated studies, appropriate sets of watershed indicators can be developed to help us better understand the human impacts on watersheds, improve our knowledge of decision making process and the information and data needs of planners and policy makers, and support more effective watershed planning and management process.

\section{Acknowledgements}

This study was partially funded by the Faculty Research and Creative Activities Support Fund of Michigan State University. 


\section{References}

Anderson, J.R., Hardy, E.E., Roach, J.T., Witmer, R.E., 1976. Land Use and Land Cover Classification System for Use with Remote Sensor Data. USGS Professional Paper 964, US Governmental Printing Office, Washington, DC.

Bailey, R.G., 1984. Testing an ecosystem regionalization. J. Environ. Manage. 19, 239-248.

Bartholic, J.F., Namken, L.N., Wiegand, C.L., 1970. Combination Equations Used to Calculate Evaporation and Potential Evaporation. USDAARS, pp. 41-170.

Beasley, D.B., Huggins, L.F., Monke, E.J., 1980. ANSWERS: a model for watershed planning. Trans. ASAE 23, 938-944.

Bicknell, B.R., Imhoff, J.C., Kittle Jr., J.L., Donigian Jr., A.S., Johanson, R.C., 1993. Hydrological Simulation Program FORTRAN User's Manual for Release 10. US Environmental Protection Agency, EPA/600/R-93/174, Anthens, GA.

Blondel, J., Cuvillier, R., 1977. Une methode simple et rapide pour decrire les habitats doiseaux: le stratiscope. Oikos 29, 326-331.

Choudhury, B.J., DiGirolamo, N.E., Susskind, J., Darnell, W.L., Gupta, S.K., Asrar, G., 1998. A biophysical process-based estimate of global land surface evaporation using satellite and ancillary data. II. Regional and global patterns of seasonal and annual variations. J. Hydrol. 205, 186-204.

Cowardin, L.M., Carter, V., Golet, F.C., LaRoe, E.T., 1979. Classification of Wetlands and Deepwater Habitats of the United States. US Department of the Interior Fish and Wildlife Service FWS/OBS-79/31.

Engman, E.T., Gurney, R.J., 1991. Remote Sensing in Hydrology. Chapman and Hall, New York.

Ferguson, B.K., 1994. The concept of landscape health. J. Environ. Manage. 40, 129-137.

Ferguson, B.K., 1996. The maintenance of landscape health in the midst of land use change. J. Environ. Manage. 48, 387-395.

Flanagan, D.C., Nearing M.A. (Ed.), 1995. USDA-Water Erosion Prediction Project (WEPP) Hillslope Profile and Watershed Model Documentation. NSERL Report No. 10, ARS National Soil Erosion Research Laboratory, West Lafayette, IN.

Fuchs, J., Tanner, C.B., 1967. Evaporation from drying soil. J. Appl. Met. 6, 852-857.

Gautier, C., Diak, G., Masse, S., 1980. A simple model to estimate incident solar radiation at the surface from GOES satellite data. J. Appl. Meteorol. 19, 1005-1011.

Gove, J.H., Martin, C.W., Patil, G.P., Solomon, D.S., Hornbeck, J.W., 1992. Plant species diversity on even-aged harvests at the Hubbard Brook experimental forest: 10-year results. Can. J. For. Res. 22 (11), 1800-1806.

Gove, J.H., Patil, G.P., Taillie, C., 1995. A mathematical programming model for maintaining diversity in uneven-aged forest stands with implications to other formulations. Ecol. Modeling 79 (1/3), 11-20.

Gove, J.H., Patil, G.P., Taillie. C., 1996. Diversity measurement and comparison with examples. In: Szaro, R.C., Johnston, D.W. (Eds.), Biodiversity in Managed Landscapes. Theory and Practice. Oxford University Press, Oxford, pp. 157-175.

He, C., Shi, C., Agosti, B.P., 1999. Development of A Window-Based GIS-AGNPS Interface. I. J. Am. Water Res. Assoc., in review.
He, C., Riggs, J.F., Kang, Y.T., 1993. Integration of Geographic Information Systems and a computer model to evaluate impacts of agricultural runoff on water quality. Water Res. Bull. 29 (6), 891-900.

He, C., Kittleson K.M., Bartholic, J.F., 1987. Evapotranspiration monitored from satellites as an indication of shift and impact of vegetation change. In: Proceedings of the 21 st International Symposium on Remote Sensing of Environment, Ann Arbor, MI, pp. 695-708.

Hobbs, R., 1997. Future landscapes and the future of landscape ecology. Landscape Urban Planning 37, 1-9.

Huber, W.C., Heaney, J.P., Nix, S.J., 1981. Stormwater Management Model. User's Manual Version III. Deptartment of Environment Engineering and Sciences, University of Florida, FL.

Jackson, R.D., Pinter Jr., P.J., Reginato, R.J., 1985. Net radiation calculated from remote multispectral and ground station meteorological data. Agri. For. Meteorol. 35, 153-164.

Jensen, J.R., Huang, X., Mackey Jr., H.E., 1997. Remote sensing of successional changes in wetland vegetation as monitored during a four-year drawdown of a former cooling lake. Appl. Geographic Studies 1 (1), 31-44.

Jensen, J.R., Cowens, D.J., Althausen, J.D., Narumalani, S., Weatherbee, O., 1993. An evaluation of the coast watch change detection protocol in South Carolina. Photogram. Eng. Remote Sen. 59, 1039-1046.

Jensen, J.R., Hodgson, M., Christensen, E., Mackey, H., Tinney, L., Sharitz, R., 1986. Remote sensing inland wetlands: a multispectral approach. Photogram. Eng. Remote Sensing 52, 87100.

Karr, J.R., Fausch, K.D., Angermeier, P.L., Yant, P.R., Schiosser, I.J., 1986. Assessing Biological Integrity in Running Waters: A Method and Its Rationale. Natural History Survey Special Publication 5, Champaign, IL.

Kelly, J.R., Harwell, M.A., 1990. Indicators of ecosystem recovery. Environ. Manage. 14 (5), 527-545.

Knick, S.T., Rotenberry, J.T., 1997. Landscape characteristics of disturbed shrubsteppe habitats in southwestern Idaho (USA). Landscape Ecol. 12, 287-297.

Larsen, D.P., Dudley, D.R., Hughes, R.M., 1988. A regional approach for assessing attainable surface water quality: an Ohio case study. J. Soil Water Conserv. 42, 171-176.

Likens, G.E., 1987. Long Term Studies in Ecology. Springer Verlag, New York.

Magurran, A.E., 1988. Ecological Diversity and its Measurement. Princeton University Press, Princeton, NJ.

May, R.M., 1981. Patterns in multi-species communities. In: May, R.M. (Ed.), Theoretical Ecology: Principles and Applications. Blackwell, Oxford, pp. 197-227.

Mattikalli, N.M., Richards, K.S., 1996. Estimation of surface water quality changes in response to land use change: application of the export coefficient model using remote sensing and geographical information system. J. Environ. Manage. 48, 263-282.

Messer, J.J., Linthurst, R.A., Overton, W.S., 1991. An EPA program for monitoring ecological status and trends. Environ. Monitoring Assessment 17, 67-78. 
Naiman, R.J., Magnuson, J.J., McKnight, D.M., Stanford, J.A. (Ed.), 1995. The Freshwater Imperative: A Research Agenda. Island Press, Washington, DC.

Omernik, J.M., 1995. Ecoregions: a framework for managing ecosystems. George Wright Forum 12 (1), 35-50.

Palmer, J.F., 1997. Stability of landscape perceptions in the face of landscape change. Landscape Urban Planning 37, 109113.

Patrick, R., 1973. Use of algae, especially diatoms, in the assessment of water quality. Am. Soc. Testing Mater., Special Technical Publ. 528, 76-95.

Pickett, S.T.A., Burch Jr., W.R., Dalton, S.E., Foresman, T.W., Grove, J.M., Rowntree, R., 1997. A conceptual framework for the study of human ecosystems in urban areas. Urban Ecosyst. 1, 185-199.

Reginato, R.J., Jackson, R.D., Pinter Jr., P.J., 1985. Evapotranspiration calculated from remote multispectral and ground station meteorological data. Remote Sensing Environ. 18, 75-89.

Sharpley, A.N., Williams, J.R., 1990. EPIC Erosion/Productivity Impact Calculator. USDA ARS Technical Bulletin No. 1768.

Southwood, T.R.E., Brown, V.K., Reader, P.M., 1979. The relationship of plant and insect diversities in succession. Biol. J. Linn. Soc. 12, 327-348.

Southwood, T.R.E., 1978. Ecological Methods. Chapman and Hall, London.

Tilman, D., 1986. Resources competition and the dynamics of plant communities. In: Crawley, M.J. (Ed.), Plant Ecology, Blackwell Scientific Publications, Oxford, pp. 51-75.

Turner, M.G., 1989. Landscape ecology: the effect of pattern on process. Ann. Rev. Ecol. Syst. 20, 171-197.

US Environmental Protection Agency, 1997. The Index of Watershed Indicators. EPA 841-R-97-010. Office of Water, Washington, DC.

US Environmental Protection Agency, 1996. Environmental Indicators of Water Quality in the United States. EPA 841-R96-002. Office of Water, Washington, DC.

Whittaker, R.H., 1970. Communities and Ecosystems. Macmillan, New York.

Wischmeier, W.H., Smith, D.D., 1965. Predicting Rainfall-Erosion Losses from Cropland East of Rocky Mountains-Guide for Selection of Practices for Soil and Water Conservation. Agricultural Handbook No. 282, USDA, Washington, DC.

Zheng, D., Wallin, D.O., Hao, Z., 1997. Rates and patterns of landscape change between 1972 and 1988 in the Changbai mountain area of China and North Korea. Landscape Ecol. 12, 241-254.

Young, R.A., Onstad, C.A., Bosch, D.D., Anderson, W.P., 1987. AGNPS, Agricultural Nonpoint Source Pollution Model: A
Watershed Analysis Tool. Cons. Res. Rpt. 35, ARS, USDA, Washington, DC.

Chansheng He is an Associate Professor in the Department of Geography, Western Michigan University. He received his B.S. and M.S. degrees from Northwestern Agricultural University, P.R. China, and his Ph.D. in Resource Development from Michigan State University with a minor in System Science. His research focuses on assessment of the effect of land use/cover change on evapotranspiration, runoff, and water quality at the watershed scale, ecosystem indicators, GIS and remote sensing applications, and comparative analysis of Sino-U.S. water resources policies.

Stephen (Steve) B. Malcolm is an associate professor of ecology in the Department of Biological Sciences, Western Michigan University. A native of the U.K., he attended the University of Oxford in England (D. Phil.), Rhodes University in South Africa (MSc.) and the University of Manchester in England (BSc. Hons), and was a postdoctoral fellow in ecology at the University of Florida and the University of London, Imperial College at Silwood Park. His research interests include the chemical ecology of interactions among plants, herbivores and natural enemies, risk assessment and biotechnology and interdisciplinary approaches to environmental and species conservation. He has worked in Europe, $\mathrm{N}$ and $\mathrm{S}$ America, Africa and Australia, and was co-founding Associate Editor of Chemoecology, an international journal of chemical ecology (1989-1997).

Kenneth A. Dahlberg is Professor of Political Science and Director of Environmental Studies at Western Michigan University. $\mathrm{He}$ is a Fellow of the American Association for the Advancement of Science (AAAS). His earlier research and writings critiqued the green revolution and sought to develop alternatives, such as sustainable agriculture. He has also done research on natural resources management and biodiversity. In recent years, his focus has broadened to an analysis of food systems. He conducted an NSF-funded project analyzing five focal food policy councils in the U.S. and more recently completed a project funded by the W.K. Kellogg Foundation to assist six U.S. communities strengthen their food policy capabilities. He is the current President of the Agriculture, Food, and Human Values Society.

Bojie Fu is Deputy Director and professor at the Research Center for Eco-Environmental Sciences, Chinese Academy of Sciences, P.R. China. His research interests are landscape ecology and land use. He got his Ph.D. degree in Physical Geography at Peking University in 1989 and as a postdoctoral research fellow at the Institute for Land and Water Management, Catholic University of Leuven, Belgium between 1992-1994. 